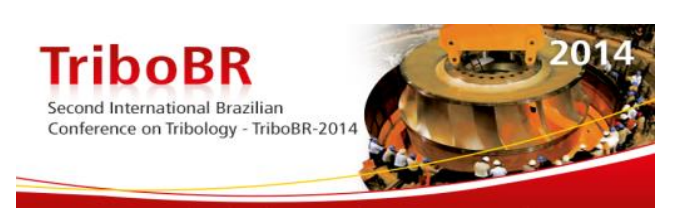

\title{
INFLUENCE OF POLYMER SHEAR THINNING ON FRICTION IN HYDRODYNAMIC CONTACTS*
}

\author{
Nigel Marx ${ }^{1}$ \\ Robert lan Taylor ${ }^{2}$ \\ Hugh Spikes ${ }^{3}$
}

\begin{abstract}
In order to understand (and ultimately to predict) the friction reduction resulting from the use of polymer solutions, the rheological properties of model polymer solutions have been measured over a wide range of shear rates. Both temporary and permanent shear thinning have been observed. By using base fluids of different viscosities it has been shown that permanent shear thinning depends more closely on the shear stress experienced by the fluid than on the strain rate. Hydrodynamic measurements have been made on the polymer solutions using a compliant ball on flat lubricated contact that operates in isoviscous-elastic conditions. The measured friction values can only be predicted with reasonable accuracy if the measured shear thinning properties of the lubricant are taken into account in the hydrodynamic model. Keywords: Viscosity modifier; Shear thinning; Hydrodynamic friction; Permanent viscosity loss.
\end{abstract}

1 PhD student, Tribology Group, Imperial College London, UK.

2 Senior Technologist, Shell Global Solutions, UK.

$3 \mathrm{PhD}$, Professor, Tribology Group, Imperial College London, UK.

\footnotetext{
* Technical contribution to the $2^{\text {nd }}$ International Brazilian Conference on Tribology - TriboBR 2014, November $3^{\text {rd }}$ to $5^{\text {th }}, 2014$, Foz do Iguaçu, PR, Brazil.
} 


\section{INTRODUCTION}

Polymer additives, initially termed viscosity index improvers but now more commonly called viscosity modifiers (VMs), have been added to vehicle engine lubricants for more than 50 years. Their primary purpose is to increase the viscosity index of their blends. They are typically long, linear chain polymers with an average molecular weight typically in the range $50 \mathrm{k}$ and $500 \mathrm{k} \mathrm{g} / \mathrm{mole}$.

One important characteristic of these additives is that their solutions exhibit shear thinning and thus show a progressive decrease in effective viscosity with rise in shear rate. Under high strain rate conditions, as are present in engine journal bearings and piston ring/liner contacts, this results in the viscosity of the formulated oil dropping significantly below its low shear rate value.

This viscosity loss can be temporary and/or permanent, depending on the fluid properties and operating conditions [1]. Temporary shear thinning results from the polymer molecules aligning under high shear rate conditions so as to reduce polymer-polymer and polymer-base oil molecule flow interactions. The equilibrium polymer configuration is restored when the fluid shear is halted, so the low shear rate viscosity is fully recovered. This type of shear thinning used to be considered undesirable since it results in a reduced effective viscosity at high shear rates and thus, potentially, thinner hydrodynamic films. However it is now recognised that temporary shear thinning is a highly desirable phenomenon in engine oils since it leads to a reduction in hydrodynamic friction in engine bearings and piston liner/ring contacts and thus contributes to improved engine fuel economy.

Permanent shear thinning originates when the forces applied to the elongated polymer molecules during shear become so great that the higher molecular weight polymer molecules present in the lubricant break into two or more fragments to give a reduction in the average polymer molecular weight. This results in a permanent decrease in blend viscosity, which persists when shear rate is lowered. It is almost always considered to be undesirable and can result in the lubricant falling "out of grade". It can be limited by the use of very narrow molecular weight distribution polymers, by deliberately removing the higher molecular weight polymers prior to use or by careful design of polymer architecture to reduce effective polymer chain length, for example by using star or brush polymers or polymer molecules linked by noncovalent and thus reformable bonds.

To appreciate the beneficial effect of temporary shear thinning on hydrodynamic friction in simple terms, it is useful to note that in most hydrodynamic contacts lubricant film thickness, $h$, varies approximately with sliding speed, $u_{s}$, and effective dynamic viscosity, $\eta_{e}$, according to;

$$
h \propto\left(u_{s} \eta_{e}\right)^{0.5}
$$

However friction force, $F$, depends on lubricant shear stress, $\tau$, which depends on the produce of effective viscosity and strain rate, $\dot{\gamma}$, i.e. velocity gradient;

$$
F \propto \tau=\eta_{e} \dot{\gamma}=\eta_{e} \frac{u_{s}}{h}
$$

Substituting Equation 1 in Equation 2 shows that friction force depends on sliding speed and effective dynamic viscosity in just the same fashion as film thickness;

$$
F \propto\left(u_{s} \eta_{e}\right)^{0.5}
$$

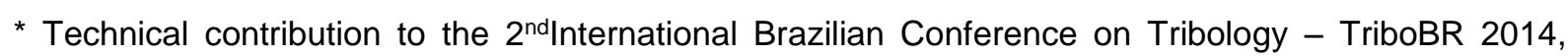
November $3^{\text {rd }}$ to $5^{\text {th }}, 2014$, Foz do Iguaçu, PR, Brazil.
} 


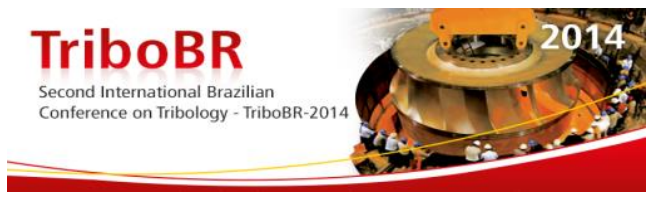

In practise, Equations. 1 and 3 imply that in low speed conditions we need a high viscosity lubricant to generate sufficient hydrodynamic film to fully separate the rubbing surfaces. But at high sliding speeds we do not need such a high viscosity the high speed contributes more strongly to the required film - so ideally we need a low effective viscosity to provide low friction. A high viscosity at low sliding speed combined with a low viscosity at high sliding speed can be achieved by having a viscosity that exhibits temporary shear thinning.

Based on the above very simple analysis (and also more complete hydrodynamic models) it is clear that to minimise hydrodynamic friction in components that operate over a range of sliding speeds we require polymer-containing lubricants to show a large amount of temporary shear thinning, (while meeting appropriate HTHS requirements), while at the same time exhibiting as little permanent shear thinning as possible.

This paper describes initial work to study VM solution shear thinning and its impact on hydrodynamic friction. The work is in four parts. First the viscometric properties of polymer solutions are measured over a wide shear rate range to quantify their temporary shear thinning properties in the form of flow curves. Secondly the permanent shear thinning properties of these polymer solutions is investigated using a new experimental technique. Then the hydrodynamic friction properties of the polymer solutions are measured. Finally the measured friction properties of the polymer solutions are compared with the predictions from hydrodynamic theory based on the measured temporary shear thinning behaviour.

\section{Test Lubricants and Experimental Methods}

\subsection{Test Fluids}

Commercially-available polystyrene polymers were used as model VM polymers. These have the advantage of very narrow polydispersivity, $I_{p}$ (MWt distribution). Their properties are listed in Table 1. Polystyrene additives are not soluble in conventional hydrocarbons so they were dissolved in aromatic ester base fluids. Four such base fluids, having different viscosities were employed as listed in Table 2.

Table 1: Polymer properties

\begin{tabular}{|c|c|c|}
\hline Solution & $\begin{array}{c}\mathrm{Mw} \\
(\mathrm{g} / \mathrm{mol})\end{array}$ & $I_{p}$ \\
\hline PS50000 & 50550 & 1.02 \\
\hline PS200000 & 214700 & 1.05 \\
\hline
\end{tabular}

Table 2: Polymer solution properties

\begin{tabular}{|c|c|c|}
\hline Base fluid & $\begin{array}{c}\text { Viscosity, cP, } \\
40^{\circ} \mathrm{C}\end{array}$ & $\begin{array}{c}\text { Viscosity, cP, } \\
100^{\circ} \mathrm{C}\end{array}$ \\
\hline Di-methylphthalate (DMP) & 7.47 & 1.86 \\
\hline Di-n-butylphthalate (DBP & 9.28 & 2.25 \\
\hline Di-n-octylphthalate (DOP) & 16.31 & 3.31 \\
\hline Di-2-ethylhexyl-phthalate (DEHP) & 26.04 & 3.91 \\
\hline
\end{tabular}

\footnotetext{
* Technical contribution to the $2^{\text {nd }}$ International Brazilian Conference on Tribology - TriboBR 2014, November $3^{\text {rd }}$ to $5^{\text {th }}, 2014$, Foz do Iguaçu, PR, Brazil.
} 


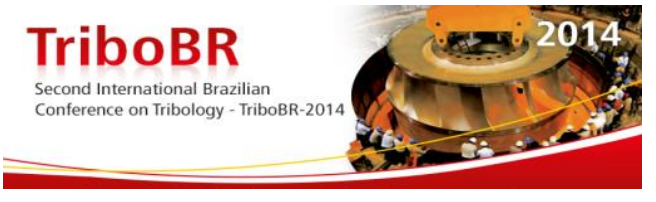

\subsection{Flow Curves}

In order to quantify the dependence of viscosity on strain rate for a range of polymer solutions, viscosity measurements were carried out using various viscometers. These include a Discovery Hybrid Rheometer in cone-plate configuration and an Ultra-high Shear rate Viscometer (USV).

The cone-on-plate viscometer measures the dynamic viscosity at a shear rate 10 to $10^{3} \mathrm{~s}^{-1}$. The USV from PCS Instruments operates between $10^{6}$ and $10^{7} \mathrm{~s}^{-1}$. The USV is based on concentric cylinders where, to address the problem of shear heating at high strain rates, the inner cylinder is only rotated, and shear stress measured over a very short time period.

\subsection{Permanent Shear Thinning}

Permanent shear thinning was measured by carrying out repeated USV tests on the same sample at a fixed shear rate and temperature, as described in [2].

\subsection{Hydrodynamic Friction Measurement}

Hydrodynamic lubrication occurs in conforming lubricated contacts when the pressure is not high enough to produce a significant piezoviscous increase in viscosity. Experimentally there are two ways to achieve such conditions. One is to use a conformal, loaded contact, for example between two flat surfaces or nearconcentric cylinders, analogous to plain thrust and plain journal bearings respectively. There are, however, significant practical problems. One is to achieve good alignment of the surfaces so as to obtain a repeatable and known film distribution. The second is that, unless the surfaces are very small, very high loads are required. A second approach, which is used in the current study, is to produce an isoviscous-elastic hydrodynamic contact by loading a ball against a flat. If one or both of the two surfaces is made of a compliant material, this gives a quite large elastically-flattened contact so that the pressure remains low enough to preclude any piezoviscous behaviour of the lubricant. The film thickness and friction of this contact can then be measured as a function of sliding speed, load etc.

In the current work polymer spheres and hemispheres were prepared and loaded against a rotating, lubricant-covered glass flat to produce a pin-on-disc configuration. The polymer hemisphere used in the work reported here was of polyethylene, with an elastic modulus of $0.8 \mathrm{GPa}$ and root mean square surface roughness of $25 \mathrm{~nm}$.

\section{RESULTS AND DISCUSSION}

\subsection{Temporary Shear Thinning}

Figures 1 and 2 show typical viscosity versus shear rate results for $50 \mathrm{k} \mathrm{MWt}$ polystyrene at two concentrations.

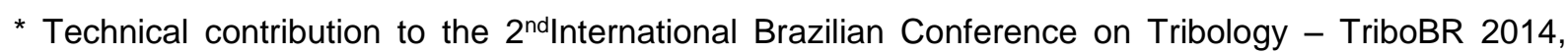
November $3^{\text {rd }}$ to $5^{\text {th }}, 2014$, Foz do Iguaçu, PR, Brazil.
} 

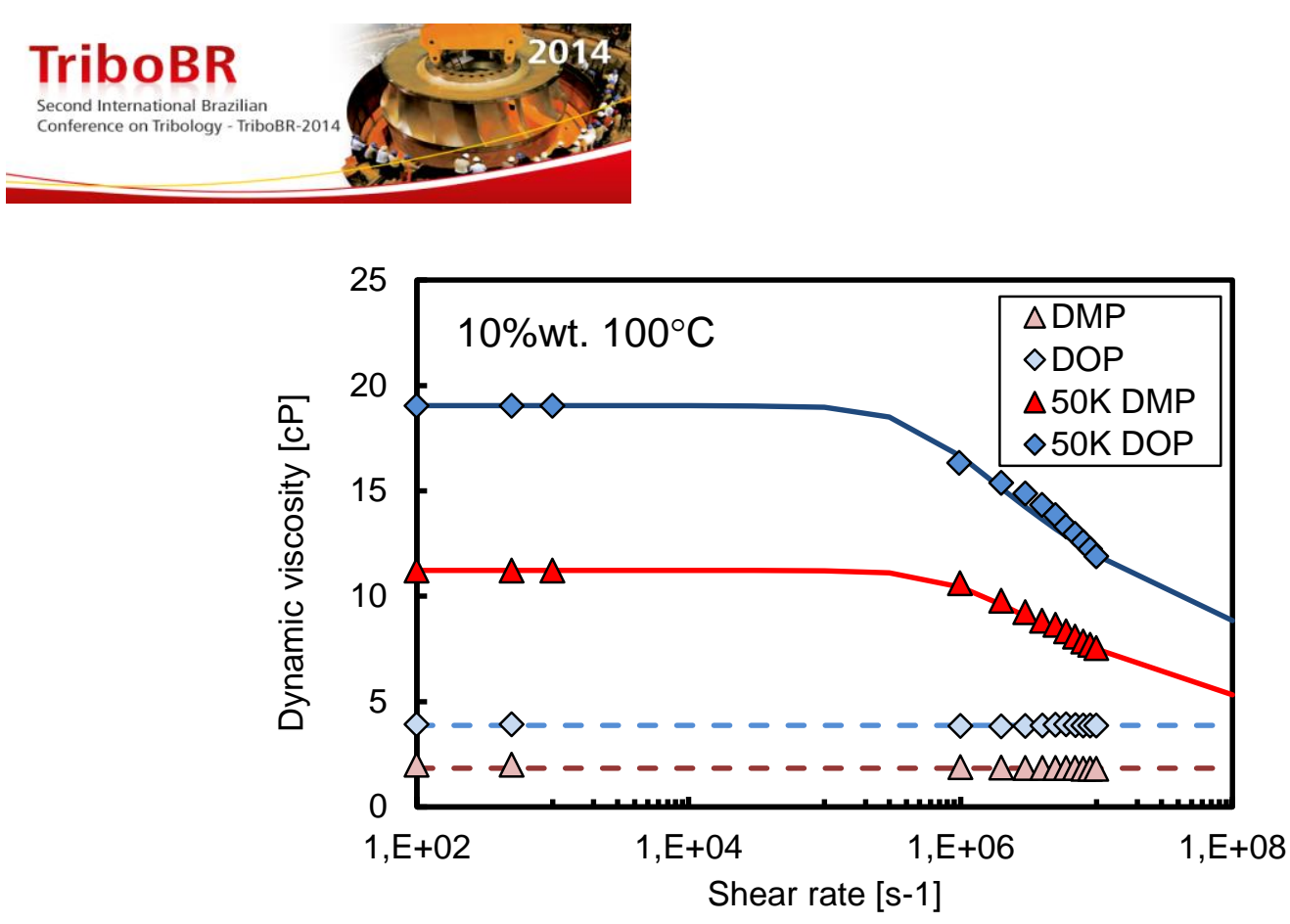

Figure 3. Carreau Yasuda equation fits to viscosity-shear rate results for $10 \%$ wt. PS solutions

\subsection{Permanent Shear Thinning}

In industry, the shear stability of polymer-containing fluids is usually evaluated by the Kurt-Orbahn test [4]. This test consists in passing a fluid through a diesel injector nozzle and in exposing the sample at $100^{\circ} \mathrm{C}$ to very high shear forces which cause the degradation of polymer molecules. After typically 90 passes through the KurtOrbahn shear stability test, the viscosity loss of VM solutions is finally measured. Crail et al. developed an identical procedure using a modified diesel injector [5]. They estimated that the shear rate should be of the order of $10^{7} \mathrm{~s}^{-1}$, which is similar to the shear rate present in the USV. In the Kurt Orbahn test the amount of permanent shear thinning is generally quantified by two indices, the permanent viscosity loss (PVL) and the Permanent Shear Stability Index (SSI). The PVL is the fraction or percentage of loss of viscosity due to shear;

$$
P V L=\frac{K V_{\text {fresh }}-K V_{\text {sheared }}}{K V_{\text {fresh }}}
$$

where $K V_{\text {fresh }}$ is the kinematic viscosity of the unsheared polymer solution and $K V_{\text {sheared }}$ is the kinematic viscosity of shear solution, both measured at low shear rate and $100^{\circ} \mathrm{C}$. The $P S S I$ is the fraction of the polymer thickening that is lost during shear;

$$
P S S I=\frac{K V_{\text {fresh }}-K V_{\text {sheared }}}{K V_{\text {fresh }}-K V_{\text {base }}}
$$

where $K V_{\text {base }}$ is the base oil kinematic viscosity

It is not possible to measure the kinematic viscosity of the sheared oil after test at low shear rate since sufficient fluid cannot be extracted from between the concentric cylinders post-test. Instead the dynamic viscosities were measured at $10^{6} \mathrm{~s}^{-1}$ in the USV at the beginning and end of the shear thinning sequence and PVL and PSSI values calculated from;

$$
\operatorname{PVL}\left(10^{6}\right)=\frac{\eta_{\text {fresh }}-\eta_{\text {sheared }}}{\eta_{\text {fresh }}}
$$

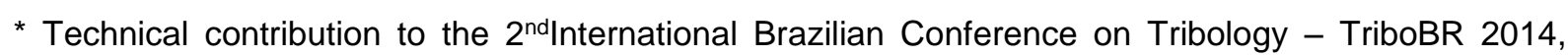
November $3^{\text {rd }}$ to $5^{\text {th }}, 2014$, Foz do Iguaçu, PR, Brazil.
} 


$$
\operatorname{PSSI}\left(10^{6}\right)=\frac{\eta_{\text {fresh }}-\eta_{\text {sheared }}}{\eta_{\text {fresh }}-\eta_{\text {base }}}
$$

where $\eta_{\text {base }}$ is the base oil dynamic viscosity, $\eta_{\text {fresh }}$ is the dynamic viscosity of the unsheared polymer solution and $\eta_{\text {sheared }}$ is the dynamic viscosity of the sheared solution, all measured at $10^{6} \mathrm{~s}^{-1}$ and the test temperate. These definitions are analogous in form to the conventional PVL and PSSI values.

Figure 4 shows typical progression of permanent shear thinning during as very prolonged test using $5 \% 200 \mathrm{k}$ polystyrene solution in DEHP. The viscosity falls due to permanent shear thinning over about 100 to 500 shearing cycles in the USV. It then levels out and starts to slowly rise again in response to further shearing cycles. This may to be due to oxidation of the polymer molecule fragments that are likely to be free radicals and thus susceptible to further reaction. To quantify the extent of permanent shear thinning, the minimum viscosity was taken, prior to subsequent increase.

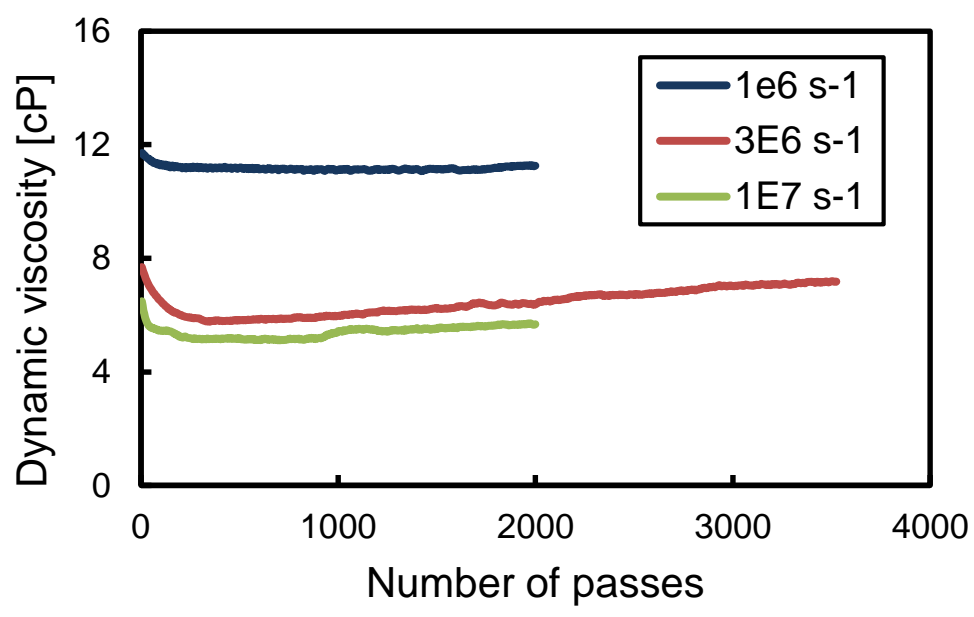

Figure 4. Evolution of viscosity due to permanent shear thinning, $5 \%$ wt.

An issue that has not been addressed in the literature is the extent to which permanent shear thinning originates from the shear stress or the strain rate. For temporary shear thinning it has been reported that shear stress is the key determinant [6] but there appears to have been no such study for permanent shear thinning.

To discriminate the effects of shear stress and strain rate, tests were carried out using the same polymers in solution in base fluids of different viscosity. This enabled viscosity loss on very similar polymers solutions to be measured at different shear stresses but the same strain rate. Figures 5 and 6 show PSSI $\left(10^{6}\right)$ plotted against shear stress and strain rate for $200 \mathrm{k}$ PS solutions tests at $80^{\circ} \mathrm{C}$. It can be seen that the results for the solutions with different solvents and thus different viscosities fall on a single curve when plotted against shear stress but not when plotted against strain rate. This suggests that permanent shear thinning depends on shear stress rather than strain rate. It implies that permanent shear thinning should become less prevalent for lubricants as base oil viscosity is reduced, all other things being equal.

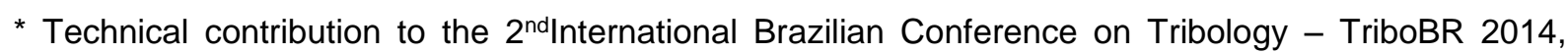
November $3^{\text {rd }}$ to $5^{\text {th }}, 2014$, Foz do Iguaçu, PR, Brazil.
} 

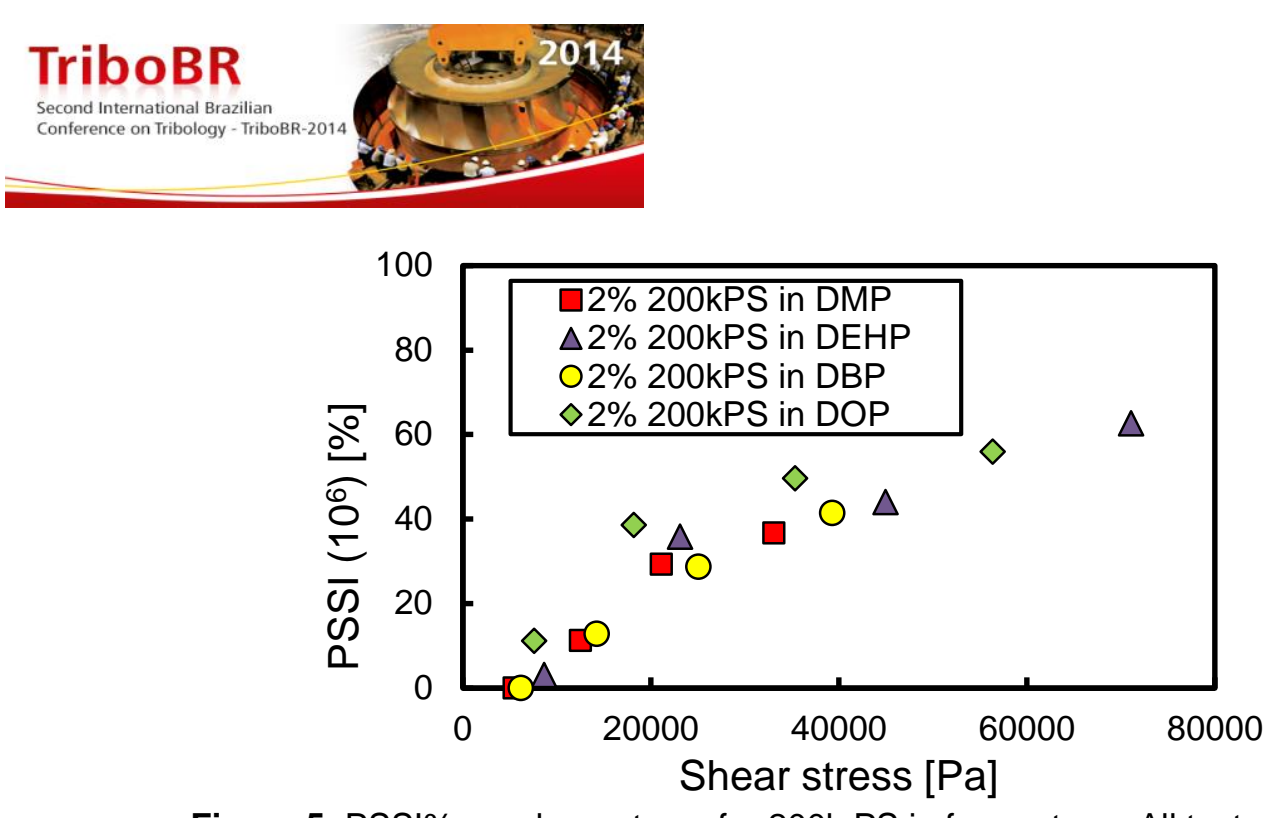

Figure 5. PSSI\% vs. shear stress for $200 \mathrm{k}$ PS in four esters. All tests at $80^{\circ} \mathrm{C}$.

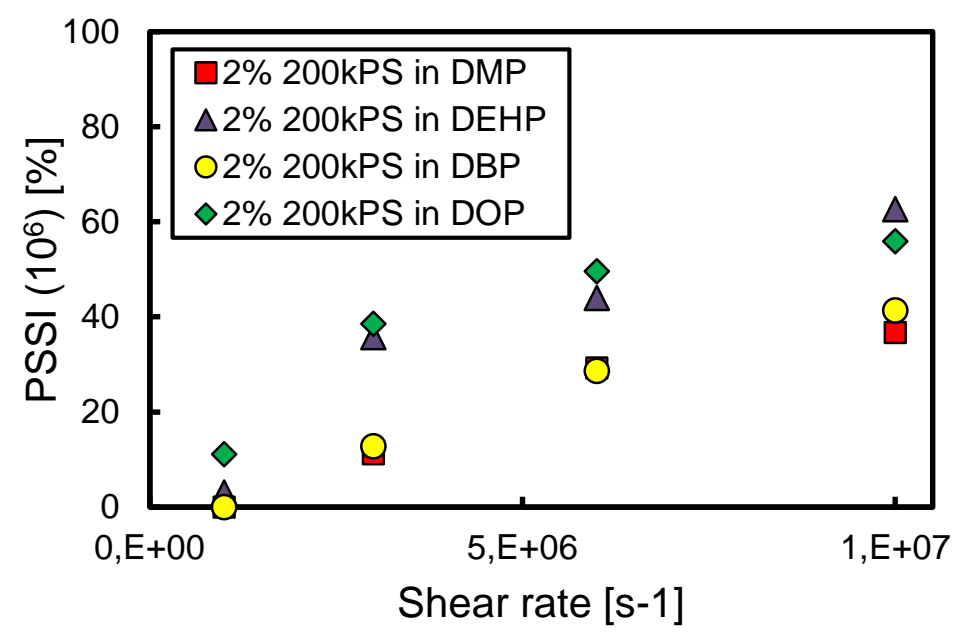

Figure 6. PSSI\% vs. strain rate for $200 \mathrm{k}$ PS in four esters. All tests at $80^{\circ} \mathrm{C}$.

\subsection{Friction}

Figure 7 shows friction coefficient measurements for an $8.35 \mathrm{~mm}$ diameter polyethylene hemisphere sliding against a glass flat lubricated with $5 \%$ wt. 50k polystyrene solution in DEHP at two temperatures.

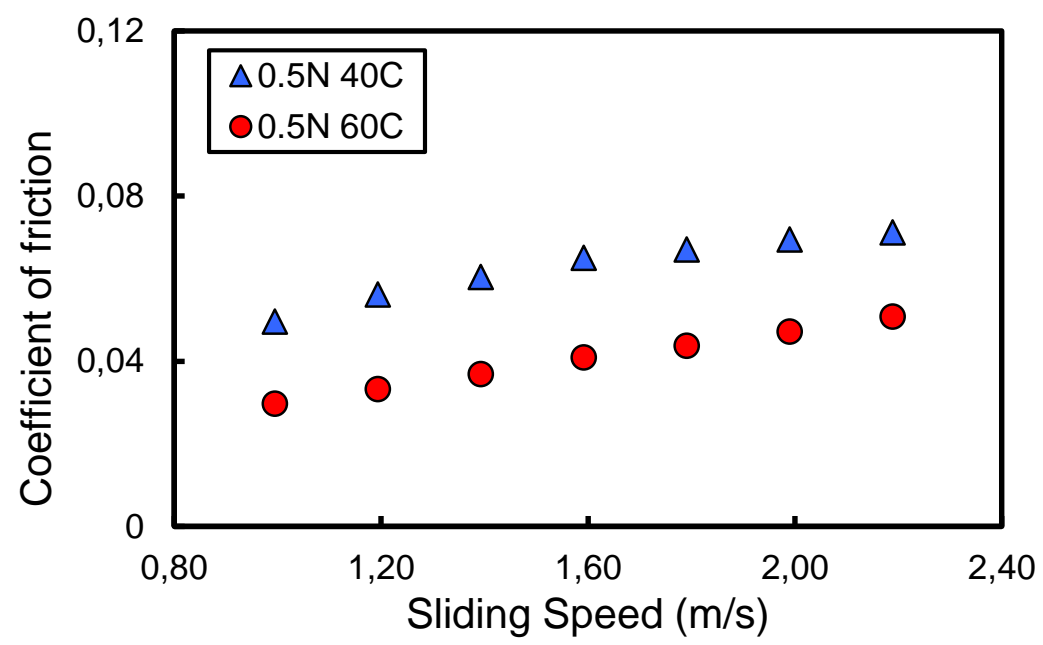

Figure 7. Influence of sliding speed on friction. 5\%wt. PS in DEHP with an $8.35 \mathrm{~mm}$ radius polyethylene hemisphere.

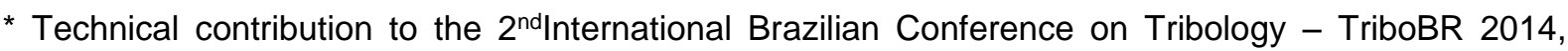
November $3^{\text {rd }}$ to $5^{\text {th }}, 2014$, Foz do Iguaçu, PR, Brazil.
} 


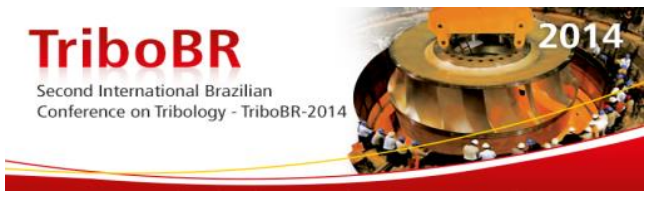

The applied load was $0.5 \mathrm{~N}$, corresponding to a mean Hertz pressure of 7.8 MPa. Friction increases with sliding speed, indicative of full film EHD conditions. Friction reduces as temperature is increased due to the consequent reduction in lubricant viscosity.

Figure 8 shows the data at $40^{\circ} \mathrm{C}$ compared to (i) prediction based on an isoviscous elastohydrodynamic model assuming no shear thinning (upper line) and (i) prediction based on the model allowing viscosity to vary over the contact due to local shear thinning.

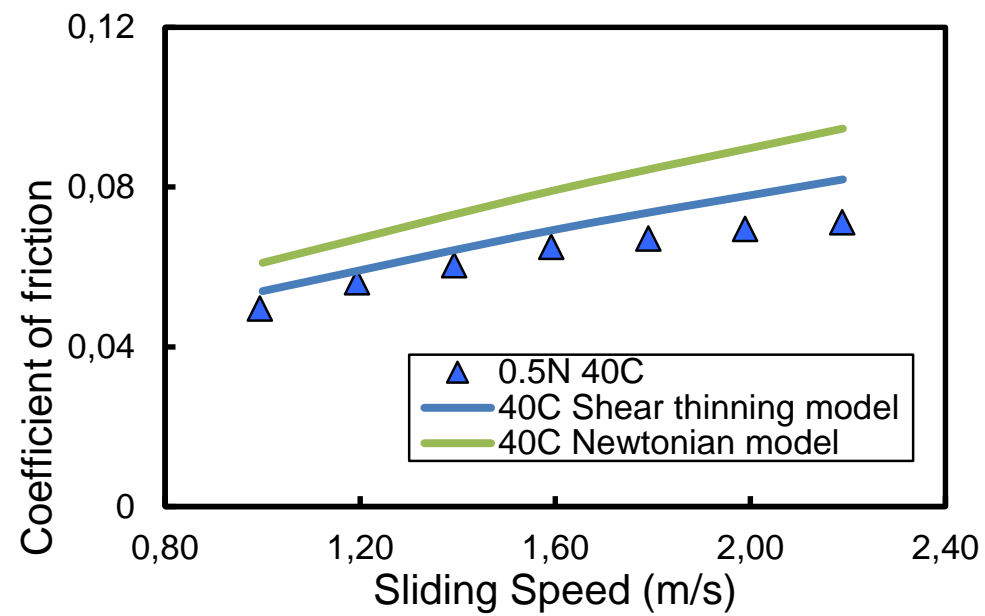

Figure 8. Comparison of predictions of Newtonian and shear thinning isoviscous-elastic hydrodynamic models with $40^{\circ} \mathrm{C}$ experimental data in Figure 5

The viscosity of the lubricant was assumed to vary according to the Carreau Yasuda equation based on measured flow curves. It can be seen that allowance for shear thinning gives improved fit to measured friction, although the fit is not perfect at high sliding speed. The model is currently being further refined to allow for variation in viscosity though the film thickness.

\section{CONCLUSIONS}

It is now recognised that the temporary shear thinning of polymer-containing engine oils is generally beneficial in terms of fuel economy since it results in a reduction in effective viscosity and thus hydrodynamic friction in high speed bearing and piston/liner contacts. The temporary permanent shear thinning properties of some model polymer solutions has been studied in order to extract flow curves. The permanent viscosity loss properties of the same fluids have also been measured. It has been shown that permanent viscosity loss depends more closely on shear stress rather than on strain rate. Hydrodynamic friction properties of the polymer solutions have also been measured using a lubricated low load, compliant ball on flat contact that operates in the isoviscous-elastic lubrication regime. The measured friction values can be quite well predicted from measured flow curves of the polymer solutions.

\section{Acknowledgments}

The authors wish to acknowledge the support of Shell for this project.

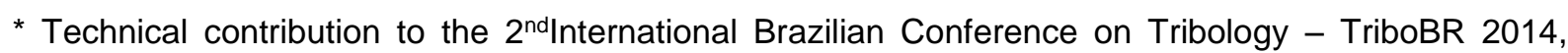
November $3^{\text {rd }}$ to $5^{\text {th }}, 2014$, Foz do Iguaçu, PR, Brazil.
} 


\section{REFERENCES}

1 Stambaugh RL, Kopko RJ. Behavior of non-Newtonian lubricants in high shear rate applications. 1973, SAE Techn. Papers 730487.

2 Holtzinger J, Green JH, Atkinson D, Lamb GD, Spikes HA., New method of measuring permanent viscosity loss of polymer-containing lubricants. Tribology Transactions, 2012, 55, 631-639.

3 Yasuda K. A multi-mode viscosity model and its applicability to non-Newtonian fluids. J. of Textile Engineering, 2006, 52, 171-173.

4 Mortier M. Laboratory shearing tests for viscosity index improvers. Tribotest 1996, 2, 329-349.

5 Crail IRH, Neville AL. The mechanical shear stability of polymeric VI improvers. J. Institute of Petroleum, 1969, 55, 100-108.

6 Horowitz $\mathrm{HH}$. Predicting effects of temperature and shear rate on viscosity of viscosity index-improved lubricants." Industrial \& Engineering Chemistry, 1958, 50, 1089-1094.

\footnotetext{
* Technical contribution to the $2^{\text {nd }} \mid$ nternational Brazilian Conference on Tribology - TriboBR 2014, November $3^{\text {rd }}$ to $5^{\text {th }}, 2014$, Foz do Iguaçu, PR, Brazil.
} 